\title{
Community Treatment Orders in Victoria, Australia
}

\author{
Paul Dedman, Consultant Psychiatrist, Community Assessment and Treatment Team, \\ Royal Park Hospital, Parkville 3052, Victoria, Australia
}

\section{The need}

It is one of the failures of contemporary psychiatry that many patients who respond well to neuroleptic medication given to them when they are in-patients relapse after discharge due to not taking any further medication. Those working closely with the acute psychiatric patient in the community are often forced to stand by powerlessly as a patient deteriorates, causing damage to himself and his social milieu until such a point is reached when he is again ill enough to warrant compulsory admission and treatment. This process is, of course, devastating for a patient's family and also disheartening for professionals involved, and is perhaps partly responsible for the high turnover of staff involved in front line services. Even if assertive outreach methods are employed such as those involved in a number of comprehensive community-based programmes (Stein \& Test, 1980; Borland et al, 1989) so that contact with the patient is not lost, it is not possible without the necessary legislation to enforce treatment in the community.

Some means of enforcing psychiatric treatment in the community is becoming a feature of the mental health law of many western countries. Three main models of legislation have emerged (Wilk, 1988). These are:

(a) as a condition of discharge from in-patient treatment (analagous to parole)

(b) as a substitute for confinement, under the principle of the least restrictive alternative (analagous to probation)

(c) preventive commitment, on the grounds of past relapse when non-compliant with treatment.

In particular, in over half of the states of the USA there is specific legislation aimed at this and in a further 20 states ad hoc legal arrangements provide alternative models of compulsory treatment in the community such as contracts or the finding of "incompetence" by a judge (Thornicroft, 1987).

In Britain the use of Section 3 of the Mental Health Act with the patient on leave, the so-called "long leash" treatment has been deemed illegal (Dyer, 1987) thus intensifying the debate over the need for, and the form of, a Community Treatment Order (Mental Health Act Commission, 1986). There is thus the potential to capitalise on the experience of the other communities who have already put such legislation into the statute book.
I would like to present a synopsis of Community Treatment Orders (CTOs) as they are currently operating in the state of Victoria, Australia.

\section{The setting}

Victoria is the smallest state of mainland Australia with a land area approximately that of Great Britain and a population of six million. Although private office-based psychiatry services the needs of many psychiatric patients, the State Health Department funds the majority of provision for patients with psychotic illness. This is composed of psychiatric hospitals, units in general hospitals and community mental health clinics. In recent years mobile Community Assessment and Treatment Teams have been established along previously described models (Stein \& Test, 1980; Hoult, 1986). The aim of these teams is both the treatment of the acute episode in the community with avoidance of hospitalisation and the follow-up of patients who have previously had relapsing conditions. Theoretically at least the teams are well placed to handle some of the extra work generated by CTOs. As with the USA, the individual states in Australia have considerable autonomy with regard to the Federal Government and are responsible for, among other things, their own mental health legislation. The Victorian Mental Health Act of 1986 is in many ways similar to the British Mental Health Act of 1983, providing the framework whereby medical decisions are subjected to the scrutiny of an independent tribunal, in line with current thinking on civil rights issues. It is of interest that the Act is written in simple English, is reasonably concise and does not necessitate the use of any guide in order to understand (and interpret) it. Although the Act can be seen as a liberalising influence, the tide of public opinion in Victoria has turned towards a position of concern over possible dangers posed to the public by those with a mental illness and there is a growing scepticism over the value of de-institutionalisation. Two unfortunate incidents occurred in Melbourne in the spring of 1988 involving indiscriminate mass shootings and resulting in the death of a dozen or so members of the public. Coverage in the popular press was sensational, and although only one of these incidents can be attributed to untreated mental illness it has established this link in the public's mind. 


\section{Legal aspects}

The Community Treatment Order was a late addition to the 1986 Act and this is evident in the minimal mention of it in the Act itself. The grounds for making a CTO are in fact not separately listed and are the same as the grounds for the admission and detention of an involuntary patient. These are:

(a) the person appears to be mentally ill

(b) the person's mental illness requires immediate treatment or care and treatment or care can be obtained by admission to and detention in a psychiatric in-patient service

(c) the person should be admitted and detained as an involuntary patient for that person's health or safety or for the protection of members of the public

(d) the person has refused or is unable to consent to the necessary treatment or care for the mental illness

(e) the person cannot receive adequate treatment or care for the mental illness in a manner less restrictive of that person's freedom of decision and action.

For CTOs the above criteria are applied as if a reference to admission and treatment were a reference to making a person subject to a CTO. Under present arrangements a person must be actually physically admitted to hospital before a CTO can be made out. However, this admission need only be a token gesture with the person present within the hospital for half-an-hour or so.

Once a patient no longer fulfills the criteria specified then they must be discharged from the CTO.

The CTO is made out by a qualified specialist (i.e. a psychiatrist of consultant status) and it must specify the medical practitioner who is to supervise the patient's treatment or care (any doctor), where the patient is to receive care, the manner and frequency with which the medical practitioner is to report to the specialist and the duration of the Order, which must not exceed 12 months in the first instance.

If a patient does not comply with the Order, or if he/she is deemed not suitable for the CTO, then the Order can be revoked and the patient compelled to return to hospital as an involuntary patient. It has not been the practice to treat patients forcibly against their will in their homes. The Mental Health Review Board must conduct a review between four and six weeks after instigation of the Order. Such a review, conducted by a lawyer, a psychiatrist and a layperson hears evidence from both treating doctor and patient. For this review a patient can be legally represented and they can also seek advice from a Mental Health Legal Advice Centre.

\section{Examples from clinical practice}

(a) A 33 year-old single mother presentes with florid psychotic symptoms including paranoid delusions and gross thought disorder. She had a history of two similar presentations over the preceding 18 months both requiring in-patient admission but resulting in non-compliance with follow-up and medication on discharge. On this occasion an attempt to treat her was made by the Community Assessment and Treatment Team by twice daily visits with the support of her parents and teenage daughter with whom she lived. Although she initially accepted medication she refused physical examination and investigations. After two days she refused further medication and began to absent herself from home, being found on at least one occasion wandering in a vague manner. She was considered to be at risk and was placed on a Community Treatment Order which necessitated her being brought to hospital for the documentation to be completed but then allowed home that day. She subsequently co-operated with assessment, investigation and treatment. The Mental Health Review Board assessed the case some five weeks later and upheld the CTO. When the CTO was due to expire after three months the patient expressed the view that she would go off treatment as soon as it did so. After much discussion with her and her family it was decided to extend the CTO, after which she again accepted treatment. We currently await the Review Board's further appraisal of the case.

(b) A 28 year-old Sri Lankan man was admitted to an in-patient unit as an involuntary patient after threatening his girlfriend with a knife. He was found to be floridly psychotic and exhibited thought disorder, passivity phenomena, grandiose delusions and auditory hallucinations. He had received a diagnosis of schizophrenia in the past and had a history of several admissions with a similar presentation followed by non-compliance with either follow-up or medication. He was a regular and frequent abuser of both alcohol and marijuana and it was not clear whether his episodes were always connected to this abuse. Treatment was initiated with oral neuroleptics and quickly converted to fluphenazine decanoate injections. He was discharged on a CTO but began to experience marked extra-pyramidal side-effects for which he was prescribed anti-cholinergics by the Community Team. At this point he refused any further fluphenazine or to consider any other form of treatment. He began to be out when he knew that a home visit was planned and when eventually confronted with the fact that he was on a CTO he laughingly replied that such a document was not worth the paper that it was written on. Given that he had experienced unpleasant sideeffects it was impossible to convince him of the benefits of medication. He remained well on no treatment for two months but relapsed and was admitted at the end of this period.

\section{Usage}

It is difficult to quantify the exact usage of CTOs in Victoria as records are not being kept centrally. My own hospital, which covers a population of approximately 600,000 , has been involved with 80 CTOs in the past 18 months. There are a number of reasons why usage of CTOs has been fairly limited. 
The wording of the Act itself and the criteria for CTO being identical to the criteria for involuntary admission can be seen as problematic. A patient in the community meeting such criteria is therefore much more likely to be admitted than placed on a CTO in the first instance. After they have received treatment for some time and are ready for discharge with symptoms resolved then they might not meet the criteria. Indeed any patient on a CTO not meeting the involuntary criteria must under the terms of the Act be discharged from it. However, in its interpretation of the Act the review board has on a number of occasions supported the notion of preventive commitment if it has been satisfied that although the patient is not currently meeting the criteria for involuntary admission, he is likely to do so if he does not continue with treatment.

At present it is also necessary for the patient to be admitted to hospital before the CTO can be made out. However this need only entail the patient having to be present in the hospital for a matter of an hour or so.

There seems to be a greater enthusiasm for CTOs among hospital staff than among staff of the community health clinics. This is perhaps understandable in terms of hospital staff feeling reluctant to see their work undone by non-compliance but not being responsible for the patient in the community. Clinic staff are used to seeing patients who elect to come and see them and may feel uneasy about entering into a relationship with a patient where there is any element of compulsion involved. The community health clinics are staffed largely by non-medical personnel who act as case managers with the back-up of psychiatrists who see the patient at less regular intervals. The training of such personnel may not have included any element of work with compulsorily detained patients and they may feel uneasy about taking on this commitment for patients under their care in the community. Many patients on CTOs do not come to clinics anyway and therefore require home-visiting. This has not been the normal working practice of the clinics in the past and obviously requires a greater input of time than clinic based sessions (both for travelling and allowing for doubling up of staff members when visiting patients who may present a risk to staff visiting alone). Accepting a patient on a CTO means that a clinic is legally bound to provide treatment and to regularly review a patient. This may involve forfeiting the previously enjoyed right of clinic staff to refuse to see a particular patient.

\section{Comment}

In conclusion it would appear that CTOs are effective only for certain groups of patients. It has been the practice that staff have not attempted to treat patients against their will in the community (for example by the administration of depot neuroleptics by force). Therefore CTOs can be seen as little more than the mechanism for streamlining of the admission procedure in cases of non-compliance. However, there are some patients who are impressed or intimidated by the CTO and whose compliance is certainly helped by it as with example (a) above. These cases of "persuading the persuadable" may represent the only situation where the CTO can be seen as having a useful outcome. Perhaps the time is now right for a large scale controlled trial of CTOs where a patient group of chronic non-compliers placed on a CTO can be compared in terms of relapse rates and social functioning with a similar group who are managed conventionally.

It would seem that in order to succeed, any CTO legislation would need to embrace the notion of preventive commitment for those with a track-record of severe illness requiring compulsory hospitalisation, non-compliance and repeated readmission. However, the ethical problems raised by this would be considerable and likely to provide a field-day for those who view the existing mental health legislation as an infringement on civil liberties.

Finally it must be noted that CTOs may also have a beneficial effect on patient care by committing the agencies involved with that patient to a firm plan of management on discharge. Thus CTOs cut both ways; they place obligations on the treating agencies to provide care as well as obligations on the patient. It follows that the success or failure of CTOs would depend on comprehensive and assertive community resources being available.

\section{References}

BORLAND, A., MCRAE, J. \& LyCAN, C. (1989) Outcomes of five years of continuous intensive case management. Hospital and Community Psychiatry, 40, 369-376.

DYER, C. (1987) Compulsory treatment in the community for the mentally ill? British Medical Journal, 295, 991-992.

HoulT, J. (1986) Community care of the acutely mentally ill. British Journal of Psychiatry, 149, 137-144.

Mental Health ACt Commission. (1986) Compulsory treatment in the community: a discussion paper. London: Mental Health Act Commission.

Stein, L. I. \& TEST, M. A. (1980) Alternative to mental hospital treatment: 1 . Conceptual model, treatment program and clinical evaluation. Archives of General Psychiatry, 37, 392-397.

THORNICROFT, G. (1987) Compulsory treatment in the community for the mentally ill?; letter. British Medical Journal, 295, 1562-1563.

WILK, R. J. (1988) Implications of involuntary outpatient commitment for community health agencies. American Journal of Orthopsychiatry, 58, 580-591. 